\title{
Scaffolding Collaborative Case-Based Learning during Research Ethics Training
}

\section{Anu Tammeleht ${ }^{1,2}$ (D) $\cdot$ María Jesús Rodríguez-Triana ${ }^{2} \cdot$ Kairi Koort $^{2} \cdot$ Erika Löfström $^{1}$}

Published online: 5 August 2020

(C) The Author(s) 2020

\begin{abstract}
As development of research ethics competencies is in the focus in higher education (HE) institutions, it is crucial to understand how to support the learning process during such training. While there is plenty of research on how to scaffold children's learning of cognitive skills, there is limited knowledge on how to enhance collaborative case-based learning of research ethics competencies in HE contexts. Our aim was to identify whether, how and when scaffolding is needed with various expertise levels to support development of ethics competencies. To identify and evaluate scaffolding during collaborative casebased ethics training we synthesised a scaffolding framework consisting of three levels: techniques, mechanisms and process. We organised 5 training sessions where 46 participants (including bachelor, master and $\mathrm{PhD}$ students as well as junior and senior academics) were involved. Data was collected as part of action research from group-work recordings and transcribed verbatim. Deductive qualitative analysis was implemented on transcripts based on the scaffolding framework. Our analysis revealed that structural scaffolding alone (learning material) is not always efficient with bachelor level students, they also require oral scaffolding when the need becomes apparent. Master's level students benefited most from wording the issues they needed to focus on. Doctoral students and senior academics needed scaffolding to maintain goal orientation. We end our article with some recommendations for facilitators of ethics education, and encourage using the scaffolding framework also in complex problem-solving beyond ethics training.
\end{abstract}

Keywords Scaffolding $\cdot$ Ethics training $\cdot$ Higher education $\cdot$ Action research

\section{Introduction}

Academic ethics and integrity are becoming increasingly important in science and academic research (e.g. results have become more accessible, the nature of publishing has changed, there

Anu Tammeleht

anu.tammeleht@helsinki.fi

1 University of Helsinki, Yliopistonkatu 4, 00100 Helsinki, Finland

2 Tallinn University, Narva mnt 25, 10120 Tallinn, Estonia 
are more opportunities for misconduct, etc.) (Bertram Gallant 2011). This means research institutions need to develop training plans and programmes to continuously develop the ethics competencies of both students and academics. The amplified focus on developing transversal skills, especially ethics and integrity, has put the training of such competencies in the forefront in higher education (HE) institutions (cf. Löfström et al. 2015; Shephard et al. 2015). In addition, how to support students during the competence acquisition and reducing this support as the competence and knowledge grow, also known as scaffolding (Wood et al. 1976), is still an open question.

In the last two decades, scaffolding has gained attention, mostly from the perspective of children's learning and focusing on cognitive skills (for a comprehensive literature review see Van de Pol et al. 2010), but not so much from the perspective of developing general or transversal competences. Research ethics and integrity does have subject content, but it can also be seen as a transversal competence needed across the fields, i.e. in research, in teaching, in collegial relations, etc. In the ethics context the individual must make value judgements about what is the best or right thing to do at a given moment. Scaffolding does not give the right answers but nudges the learner forward giving direction to explore value standpoints without telling what is right or wrong. These are the main motivations why we considered specifically scaffolding as a useful pedagogy in this particular context.

(a paragraph added)

There is some research on how scaffolding has been used to develop certain transversal competences, e.g. communication skills among pharmaceutical students (Planas \& Nelson 2008) and teamwork skills among Business undergraduates (Jackson et al. 2014), but detailed analysis of various scaffolding techniques was not present in those studies. Kim and Hannafin (2011) have researched scaffolding problem-solving, where the focus of learning was on the process rather than content, where scaffolding supported gradual development, still, their study focused on children's learning. However, there is very little evidence on how scaffolding can support developing ethical competencies (e.g. Pijanowski 2009; Turner and Berkowitz 2005). We use the word 'competency' (plural 'competencies', as set of skills, knowledge, abilities), instead of 'competence' (not often used in plural, general ability, plural 'competences') as explained by Suciu \& Mâță (2010).

The purpose of the current paper is to shed light on how to teach ethical competencies in the HE context with a focus on whether, how, and when scaffolding is required based on the expertise level of the learner. The article reports on the lessons learned from 5 training sessions with a total of 46 participants who worked in 15 groups, including bachelor, master and $\mathrm{PhD}$ students as well as junior and senior academics. During those sessions 2 facilitators scaffolded the student work structurally and orally. Data were collected as part of action research and consisted of recorded group-work presentations. Data were analysed deductively based on the scaffolding framework synthesised for this study. The results will help facilitators of ethics training to provide scaffolding structurally and orally to best facilitate the acquisition of ethics competencies.

\section{Scaffolding the Learning Process: The Concept, Techniques and Evaluation}

The term 'scaffolding' was introduced by Wood et al. (1976) and entails providing support to students when needed and fading it as the learner gains competence. Originally, scaffolding 
was considered an interaction where the 'expert' (e.g. a parent, teacher or tutor according to Wood et al. (1976), or a peer, as added by Vygotsky (1978) later on) provided the help needed by the learner e.g. reducing the complexity of the task, maintaining goal orientation, motivating or providing answers (Wood et al. 1976). Turner and Berkowitz (2005) also report that in the original scaffolding concept three characteristics had to be present: a) scaffolding is a social process; b) scaffolding happens through social tools and most particularly, language; and c) scaffolding as an outside help gradually disappears (fades). In addition, Turner and Berkowitz (2005) support peer scaffolding by stating that student-to-student scaffolding is preferred by learners as the other student does not usually exceed the learner's zone of proximal development. In the current article we refer to scaffolding as external support provided to learners during collaborative learning where the support is included in the training design or provided orally by facilitators and peers as the need becomes apparent, and fades when the expertise of the learners grows.

The concept of scaffolding has moved from personal tutoring into classrooms, where the very personal approach is not possible anymore (Puntambekar \& Hübscher 2005). This means scaffolding is adopting new forms to support learning in the classroom, e.g. instructions are provided on paper or online environments that help restructure the bigger tasks, expert knowledge comes in the form of a text, etc. However, Puntambekar and Hübscher (2005) highlight the challenges with this 'structural' scaffolding as it may not target the aspects of various levels of learner's previous knowledge, gradual fading and overall organisation of the class, that are present in the original concept of scaffolding.

Naturally, scaffolding does not apply only to children's learning, but can be used in any field of life - from students in HE institutions to seniors learning to use the internet. While there are studies of scaffolding in HE contexts, there are not so many available that would focus on scaffolding transversal skills like ethics and integrity. For example, Planas \& Nelson (2008) studied scaffolding acquisition of communication skills among pharmaceutical students and Jackson et al. (2014) researched development of team-work skills among business students, only very few report scaffolding ethics or moral education. Turner and Berkowitz (2005) describe the socio-cultural origin of scaffolding and argue why it would be beneficial to use it in moral and character education. Pijanowski (2009) emphasizes that an effective college ethics curriculum would include metacognition, cross-contextual dilemma discussions as well as scaffolded moral decision-making, and also lists some scaffolding techniques that could be adopted (e.g. decomposing the bigger task into smaller units, maintaining goal orientation, highlighting critical features and discrepancies and providing examples/ideal answers). Dempsey et al. (2001) talk about scaffolding in the context of professional self-construction (in social work) where personal values and professional ethics are in a dominant position. For scaffolding reflective learning they suggest including facilitators, but also a lot of structural scaffolding, e.g. a portfolio with quite prestructured sections (Dempsey et al. 2001).

How effective is scaffolding? Van de Pol et al. (2010) examined a decade of scaffolding research and concluded that there is a very small number of effectiveness studies, most of which focus on measuring effectiveness with a pre- and post-test, one-to-one tutoring and children acquiring content knowledge. They (Van de Pol et al. 2010) also bring out the main challenge of studying effectiveness of scaffolding - namely measurement. Scaffolding is difficult to measure due to its complex and dialogic nature (Van de Pol et al. 2010). Van de Pol et al. (2010) suggest having a clear coding system of scaffolding techniques, where the unit of analysis is clarified (like the one used in Chi et al. 2001). Still, it was admitted (Van de Pol 
et al. 2010) that due to no consistent measurement framework it is difficult to compare different studies as results depend greatly on the units of analysis.

Nevertheless, there are some studies that have considered overall effectiveness of scaffolding in acquiring domain-specific knowledge and metacognitive skills. Raes et al. (2012) studied the effectiveness of scaffolding provided by teachers and technology - they concluded that students with limited prior knowledge benefit most from teacher-mediated scaffolding as the teacher can diagnose what sort of help is needed. At the same time, more advanced students will progress regardless of scaffolding format (Raes et al. 2012). Pijanowski (2009) looked into scaffolding moral decision-making and highlighted that the teacher should be taking the role of a facilitator rather than an authority, whose role is to create the optimal learning environment and structure the learning process to support students focus on relevant aspects. Raes et al. (2012) also point out that to cater for the needs of students of different levels, the facilitator should use multiple scaffolding strategies (both structural and oral).

\section{Scaffolding Framework}

As pointed out by Van de Pol et al. (2010), there is no one scaffolding framework for analysing scaffolding on different levels. After consulting various studies, a framework for the current study was synthesised consisting of three layers for our scaffolding analysis:

1 Chi et al. (2001) outline a framework of scaffolding techniques and criteria for evaluation of scaffolding effectiveness (also recommended for evaluation by Van de Pol et al. (2010). Chi et al. (2001) consider scaffolding a critical constituent in accelerating learning, highlighting two components of scaffolding: what to say and when to say it. Chi et al. (2001) framework gave our framework the core in the form of scaffolding techniques.

2 Reiser (2004) claims that scaffolding has 2 complementary mechanisms - structuring the task and problematising the subject matter. Structuring the task means reducing the degree of freedom and maintaining focus (e.g. decomposing complex tasks, focusing effort by giving limited options/pre-selecting data, helping learners monitor what they are learning by using prompts/reminding about important goals, etc.) (Reiser, 2004). Problematising means making the learner's work more 'problematic' thus eliciting the use of previous experience to solve the problem (e.g. extending the case/problem, highlighting 'discrepancies', providing help only when asked, keeping the focus, eliciting commitment by provoking learners, etc.) (Reiser 2004). According to Reiser (2004) some scaffolding techniques help structure the problem in a way that it is easier for learners to approach it, while some scaffolding techniques make the object of learning more problematic to show learners different aspects of it. Reiser's (2004) concepts gave our framework the layer to evaluate scaffolding mechanisms.

3 Quintana et al. (2004) have developed a scaffolding process framework that specifically targets key challenges that learners face, namely - sense-making, process management and articulation/reflection. First, content knowledge is important as this will help with sense making. Second, the learner will be provided support on which strategy to use and it should be made explicit. Third, to help with articulation and reflection, attention should be paid to language, discourse markers and terminology. Quintana et al. (2004) also claim that beginners tend to focus on superficial details, and they fail to see the underlying structure, which is visible to the more advanced learners. Beginners should, thus, be 
prompted to reflect and focus on knowledge and conceptual understanding. Quintana et al. (2004) emphasise that scaffolding should first focus on sense-making - so content knowledge is important. Next, scaffolding should support process management by dividing a more complex task into smaller ones and guide the order of steps. Articulation and reflection can follow when a certain level of understanding has been achieved and the learner has sufficient vocabulary to do so (Quintana et al. 2004). Quintana et al.'s (2004) framework gave us the layer for evaluating the process of scaffolding.

Table 1 outlines the scaffolding framework for analysis in the current study. The core of the framework has scaffolding techniques outlined by Chi et al. (2001) and build into a more coherent structure by Tambaum (2017). The only technique not present in Chi et al. (2001) was 'extending the case', which was pointed out by Reiser (2004) and was difficult to pinpoint in the Chi et al. (2001) original framework, and was thus added. The scaffolding techniques are explained and illustrated by examples. The next layer in the framework (to the left of the techniques) is provided by Reiser (2004) in the form of scaffolding mechanisms - S for structural mechanism, and $\mathrm{P}$ for problematising mechanism. Structural mechanism can be included in the instruction or task design, problematising is usually provided orally as the need for it is dependent on the learner's responses. Another layer was added to the scaffolding framework (the first column) and this is the scaffolding process framework by Quintana et al. (2004). Scaffolding should start with supporting sense-making as the learner must first understand the concepts and have knowledge in order to start solving complex problems. Then learners usually require support in managing the process, and eventually in articulation and reflection.

In order to evaluate the necessity and effectiveness of scaffolding, we used the framework to analyse the use of scaffolds in a series of ethics training sessions which were part of action research. The following research questions were posed:

1 Which scaffolding techniques were used?

2 Were the used scaffolding techniques effective?

3 What were the similarities and differences of scaffolding techniques between various expertise levels?

Two different ethics training workshops were designed: Foundation level and Advanced level (see the description below and the Appendix). It should be noted that even if the content addressed in each level was different, the scaffolding techniques remained the same so that our lessons learnt across levels could be compared.

\section{Description of Scaffolding in Workshops Designed for the Study}

To help develop research ethics competencies in HE institutions, research ethics workshops were designed that utilised cases, collaboration, and structural and oral scaffolding. There were two different formats of dealing with cases - the first format (Foundation Level) consisted of groups initially dealing with ethics cases independently (receiving only structural scaffolding provided by the design of the tasks), then presenting the results and simultaneously receiving oral scaffolding by facilitators (expert teachers). The other format (Advanced Level) consisted of groups dealing with cases and simultaneously receiving structural and oral scaffolding. 


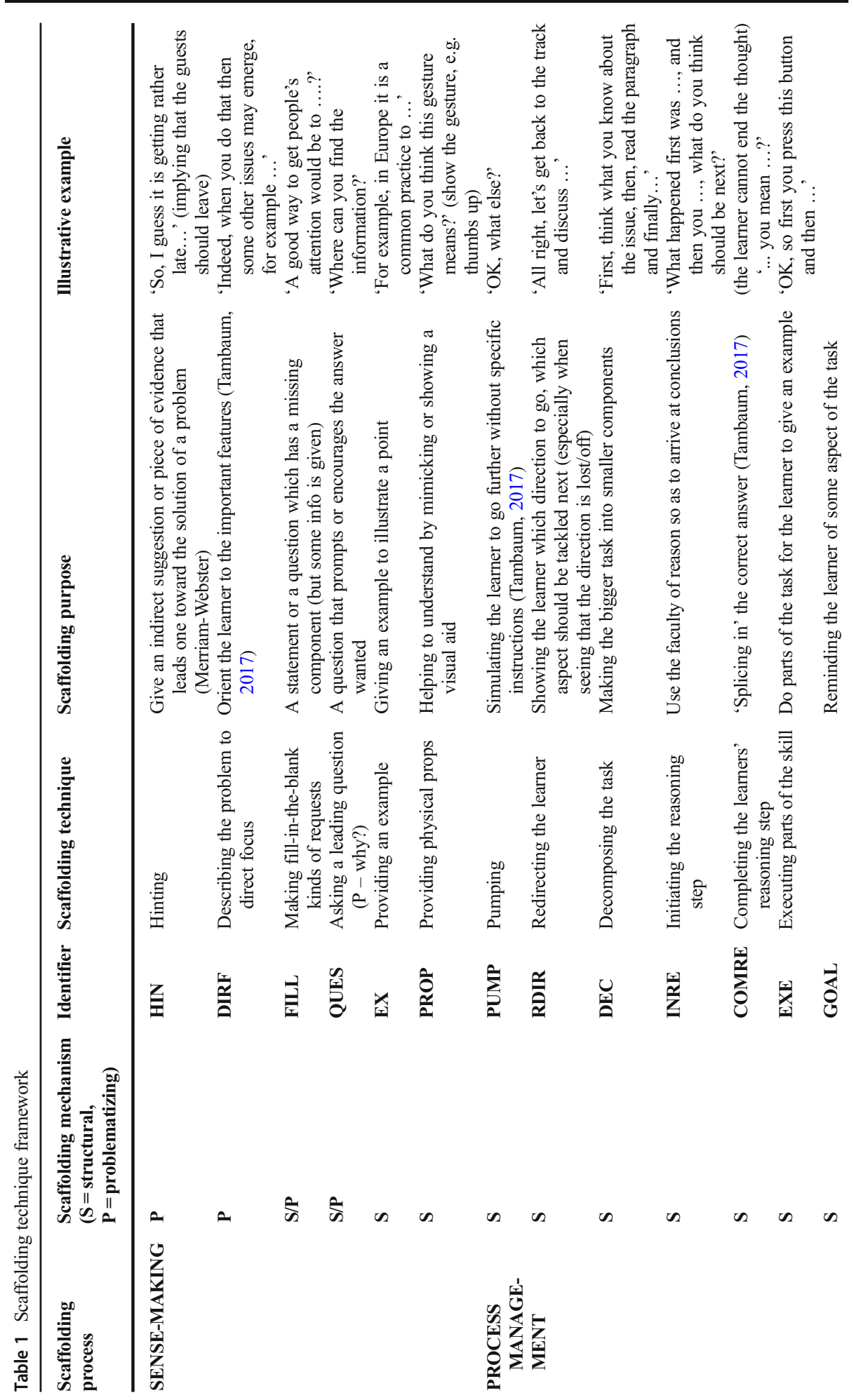




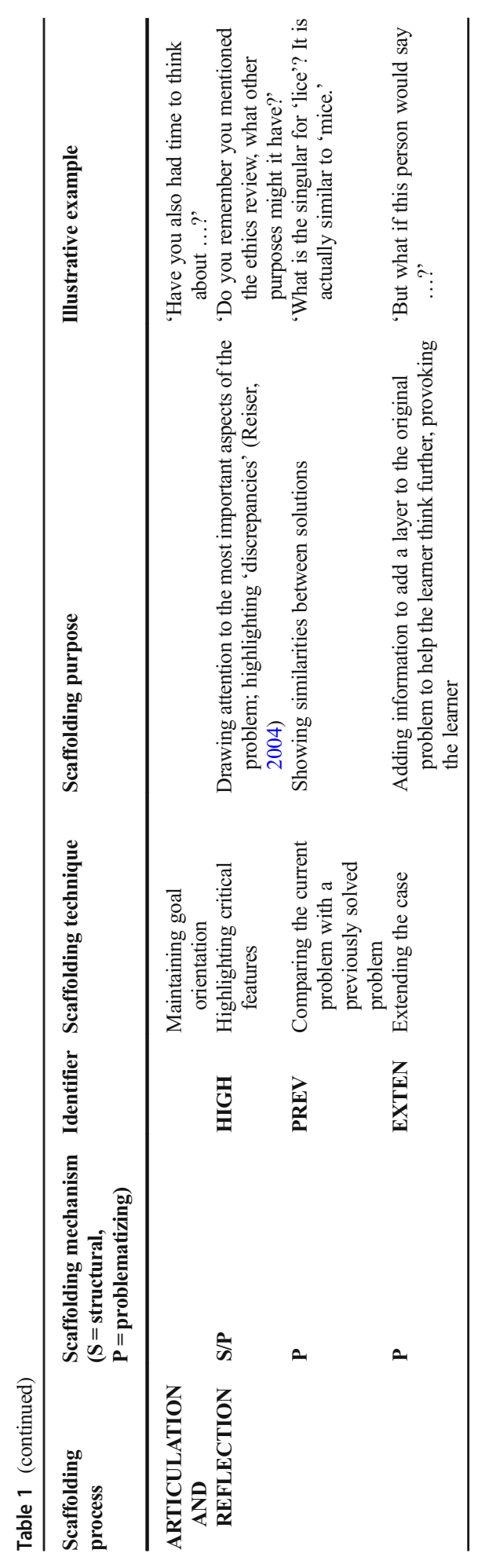


There was also one group who received passive scaffolding (the facilitator being there but not offering support). See the Appendix for a detailed description of the workshops.

While structural scaffolding was built in the training design purposefully, the duringtraining scaffolding was intuitive and was based on the needs of the learners. Oral scaffolding was not pre-planned, as based on the level of the learner's understanding a facilitator tailors the scaffolds that are needed. Reiser (2004) also emphasises that the learners, tools (i.e. training materials) and facilitators should form a coherent system of scaffolding.

The ethics training resource was designed so that some scaffolding was provided already through the design of the tasks. The first format of ethics workshop (Foundation level, designed primarily for bachelor, master and beginner $\mathrm{PhD}$ students) included the following structural scaffolding:

a decomposing the task (DEC - see identifiers in Table 1) was included in the design resource - the material was divided into 4 different tasks providing support as appropriate;

b questions were provided for the discussion to redirect the learner (RDIR); maintain the goal (GOAL); ask leading questions (QUES); highlight critical features (HIGH);

c support material was then provided which led the group to compare the answers they had provided with the ethics regulations (PREV, HIGH);

d during the presentations various oral scaffolding techniques were provided by one or two facilitators who conducted the ethics workshop.

The Advanced level ethics workshop included the following structural scaffolding:

a decomposing the task (DEC) was included in the design resource - the material was divided into 3 different sections;

b questions were provided for the discussion to redirect the learner (RDIR); maintain the goal (E); ask leading questions (QUES); highlighting critical features (HIGH) (but was more general than for the Foundation Level workshop);

c during the discussion various oral scaffolding techniques were provided by a facilitator.

The workshops are designed to be used one after another, so the structural scaffolding fades as the expertise level of the learner increases (as can be seen in Table 2).

\section{Research Method}

To answer the research questions, data were collected as part of action research (Stringer, 1999), doing a systematic, reflective study of the pedagogical intervention, and the effects of scaffolding during 5 workshops organised for beginner and more advanced researchers. Data

Table 2 Overview of structural scaffolding in the task design

\begin{tabular}{llll}
\hline Timing & Provided scaffolding & Foundation Level & Advanced Level \\
\hline Group work & Structural - Decomposing the task & DEC & DEC \\
Group work & Structural - Questions & RDIR, GOAL, QUES, HIGH & RDIR, QUES, HIGH \\
Group work & Structural - Support material & PREV, HIGH & - \\
Presentation & Oral & On demand & On demand \\
\hline
\end{tabular}


(from recorded group presentations) were analysed qualitatively - deductive content analysis based on the scaffolding framework synthesised for this study (Table 1). The aim was to focus on in-depth analysis of cases (student group learning) and not on quantitative analysis which are more appropriate for generalisation.

\section{Context}

The Estonian higher education system follows the model developed in Bologna Process where bachelor, master and doctoral studies involve certain amount of research work. All BSc students lead an individual research project that forms the experimental part of their written final thesis. Bachelor curricula students' studies (in different fields) can culminate either with the defence of literature overview analysis or experimental thesis. In addition, bachelor students in Educational Sciences are expected to conduct small scale research which may include children. For graduation, the master's students write a research thesis equivalent to one research paper and are encouraged to publish in scientific journals. Both the undergraduate and graduate theses work can require the acquisition of ethical authorisation. Regarding $\mathrm{PhD}$ students, the doctoral programme lasts nominally for 4 years and consists of 240 credits, out of which 180 credits are nominated for research work.

\section{Participants and Data Collection}

Data were collected during a series of workshops for BA/BSc, MA/MSc, PhD students and supervisors. There were 46 participants ( 15 bachelor students, 12 master students, 11 doctoral students, 8 supervisors working in 15 groups from an Estonian university). Students represented social and behavioural sciences as well as natural sciences backgrounds, supervisors represented a wider variety of fields.

Data were collected from oral group presentations/discussions which were video- or audiorecorded (a total of $3 \mathrm{~h}$ and $18 \mathrm{~min}$ ) and speech was transcribed verbatim.

Foundation level ethics workshop was taken by 5 groups of bachelor students, 5 groups of master students and 2 groups of doctoral students. Groups spent about $45 \mathrm{~min}$ on the case and discussion and then about 10 min on presentation (per group). The groups had one or two facilitators. The facilitators had prior experience in teaching research ethics, but they were not trained for scaffolding and they used scaffolding techniques in slightly different ways depending on their interpretation of the situation and the target group.

On the Advanced level, 3 groups worked on cases, one consisting of $\mathrm{PhD}$ students, two consisting of graduate and post-graduate student supervisors. All groups spent about 25 min on the case. The tasks were focused on different topics, but initial tasks contributed to achieving the outcome of task 3 . One supervisor group had a facilitator, while the other mostly did not (passive scaffolding). The $\mathrm{PhD}$ group had a facilitator most of the time (except for the last task - possible courses of action). See the Appendix for detailed workshop descriptions.

\section{Data Analyses}

As a starting point we used the Ethics Case Assessment Grid (ECAG) to evaluate the effectiveness of structural scaffolding included in the task design (Tammeleht et al., 2019). This gave us insight on which structural scaffolding techniques were most effective for different participant groups. 
For the oral scaffolding analysis, all the audio and video files were transcribed verbatim, groups were given codes based on the degree/expertise level and a group number. Contents related to the different scaffolds were marked with that code (e.g. 'BA_G1' denoting bachelor level students belonging to group 1, other level codes being 'MA', 'PhD' and ' $\mathrm{S}$ ' for 'master', 'doctoral' and 'supervisor' respectively, advanced level groups also had a code 'Ad') to keep track of which scaffolds were used with different degree levels. From the transcriptions all the interventions by the facilitators and student responses to them were analysed based on the scaffolding framework (see Table 1). Transcriptions were analysed using content analysis, relating the quotes from the transcripts to the proposed framework. The unit of analysis was a whole thought that could comprise of a few words (e.g. 'OK, what else?') to several sentences ('You mentioned .... Have you also considered...?').

In addition, the effectiveness of the scaffolding was evaluated based on: first, effectiveness on the topic evolvement, and second, effectiveness on scaffolding based on student responses (moving forward, but not advancing significantly overall). By 'effectiveness' we mean that the scaffolding technique achieved its original purpose (see column 'Scaffolding purpose' in Table 1). For example, the scaffolding technique 'maintaining goal orientation' is meant to remind the learner of some aspect of the task and if the learners' discussion or train of thought moves toward the intended topic, the technique was effective. See the following examples of, first, an effective outcome of a scaffolding technique, and then an ineffective outcome:

(S_Ad_G1) Facilitator: So, the first task is to recognise the ethical issue, it may be hidden, or it may be staring at us, like, in the face....

Supervisor 3: I think it facing us, it's not hidden, it's obvious ...

Supervisor 2: Yes, it's plagiarism. [GOAL - effective].

(S_Ad_G1) Facilitator: But can they rely, for example, on the codes of conduct? ... For example, we have this 'Hea Teadustava' in Estonia ...

Supervisor 3: yeah...

Table 3 Scaffolding techniques used with the different groups and occurrence

Occurence of scaffolding techniques used

\begin{tabular}{|c|c|c|c|c|c|c|c|c|}
\hline \multirow[b]{2}{*}{$\begin{array}{l}\text { Scaffolding } \\
\text { process }\end{array}$} & \multirow[b]{2}{*}{$\begin{array}{l}\text { Scaffolding } \\
\text { technique }\end{array}$} & \multicolumn{3}{|c|}{ Foundation level } & \multicolumn{2}{|c|}{ Advanced level } & \multirow[b]{2}{*}{ PhDs } & \multirow[b]{2}{*}{ TOTAL } \\
\hline & & Bachelors & Masters & PhDs & $\begin{array}{l}\text { Supervisors } \\
\quad 1\end{array}$ & $\begin{array}{l}\text { Supervisors } \\
\quad 2\end{array}$ & & \\
\hline \multirow[t]{6}{*}{ Sense-making } & HIN & 0 & 0 & 0 & 0 & 0 & 0 & $\mathbf{0}$ \\
\hline & DIRF & 9 & 0 & 0 & 0 & 0 & 2 & 11 \\
\hline & FILL & 1 & 12 & 0 & 5 & 0 & 3 & 21 \\
\hline & QUES & 12 & 28 & 5 & 5 & 2 & 8 & 60 \\
\hline & EX & 14 & 30 & 2 & 2 & 0 & 3 & 51 \\
\hline & PROP & 0 & 0 & 0 & 0 & 0 & 0 & $\mathbf{0}$ \\
\hline \multirow{6}{*}{$\begin{array}{l}\text { Process } \\
\text { management }\end{array}$} & PUMP & 3 & 7 & 2 & 1 & 1 & 6 & 20 \\
\hline & RDIR & 0 & 1 & 1 & 0 & 1 & 6 & 9 \\
\hline & DEC & 0 & 0 & 0 & 0 & 0 & 0 & $\mathbf{0}$ \\
\hline & INRE & 0 & 0 & 0 & 0 & 0 & 0 & $\mathbf{0}$ \\
\hline & COMRE & 2 & 0 & 0 & 0 & 0 & 2 & 4 \\
\hline & EXE & 0 & 2 & 0 & 5 & 0 & 6 & 13 \\
\hline \multirow{4}{*}{$\begin{array}{l}\text { Articulation } \\
\text { and } \\
\text { reflection }\end{array}$} & GOAL & 0 & 5 & 0 & 0 & 3 & 7 & 15 \\
\hline & HIGH & 0 & 5 & 7 & 9 & 0 & 0 & 21 \\
\hline & PREV & 1 & 0 & 0 & 0 & 0 & 0 & 1 \\
\hline & EXTEN & 3 & 2 & 0 & 0 & 0 & 1 & 6 \\
\hline \multicolumn{2}{|c|}{ TOTAL } & 45 & 92 & 17 & 27 & 7 & 44 & 232 \\
\hline
\end{tabular}


Table 4 Effectiveness of the scaffolding techniques

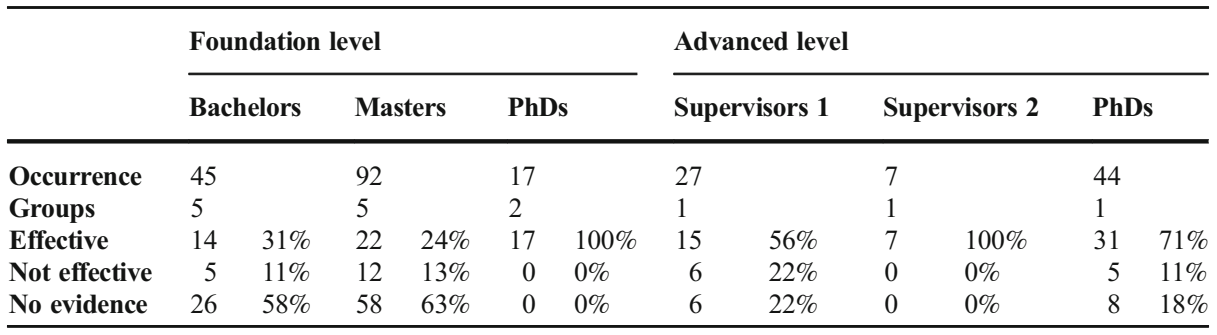

Facilitator: We have ALLEA code for Europe... all over Europe [pause]. Maybe they can rely on that if they cannot agree on responsibilities .... There is an entry about this - like, 'who is the author of this idea'... maybe refer to some documents?

Supervisor 4: I think that the supervisor should also think about that, it is not the end of life. [FILL; EXE - not effective].

\section{Research Ethics}

The research followed the European Code of Conduct for Research Integrity (The European Code of Conduct for Research Integrity 2017) and the Estonian Code of Conduct for Research Integrity (Tartu University Centre for Ethics \& Research Ethics Council 2017). Participation was voluntary and based on informed consent, which the participants had the right to withdraw at any time. Participation/non-participation in the research did not influence the participants' status in the course or in their studies. The data were anonymised before analyses. The Estonian code of conduct does not provide guidance on ethics review. As two of the authors are affiliated with a Finnish university, it appeared reasonable to apply the Finnish Advisory Board on Research Integrity Ethics (2009) guidelines for research in the humanities and social and behavioural sciences. According to these guidelines, a study such as the one presented here does not require an ethics review (i.e. it did not involve an intervention in the physical integrity of research participants; deviate from the principle of informed consent; it did not involve participants under the age of 15 being studied without parental consent; it does not expose participants to exceptionally strong stimuli; it is not prone to cause long-term mental harm beyond the risks encountered in normal life; and it does not signify a security risk to subjects, cf. Finnish Advisory Board on Research Integrity 2009, 3).

\section{Results}

This section reports the insights gained from the analysis of the scaffolding provided to the groups of Foundation and Advanced level. An overview of the techniques used and the occurrence per group is provided in Table 3, and Table 4 shows the perceived effectiveness of the scaffolding.

There was one scaffolding technique that was not used at all (in the task design or orally) providing physical props. The reason could be that this technique might be more suitable for children or with more specific subject studies - as this was not the case in our study, this technique was not used. 


\section{Foundation Level Scaffolding}

The analysis of structural scaffolding showed (based on ECAG analysis, Tammeleht et al. 2019) that different types of techniques resulted in various outcomes with different participant groups. The learners worked in groups, which already provided peer scaffolding as more knowledgeable peers started tutoring less experienced ones and support was provided by the discussion within the group.

For bachelor students the initial awareness of ethical issues was relatively low, recognising one or two topics out of 6-7 (see the Appendix for a detailed description of the workshops). Using the language to word the issues in task 2 provided some help (helped recognise one or two additional topics). With the help of support material (task 3) understanding of one or more additional topics showed increased understanding. The greatest increase in understanding (noticing topics and understanding relations between them) happened during the presentation and oral scaffolding task.

The initial awareness of master students was almost as low as that of the bachelor students, but they recognised most ethical issues when the topics were worded in task two. Support material helped some groups improve understanding of one or two topics and the groups showed only minor increase of understanding during the presentation task.

$\mathrm{PhD}$ students usually recognised one or two topics during the first task, but wording the topics in task two showed that they actually had understanding and were able to see connections between them as well. Oral scaffolding helped only slightly (pointing out one or two topics and providing explanations to them).

Analysis of oral scaffolding showed various scaffolding mechanisms and scaffolding techniques that were used during the presentation task. See Table 3 for an overview of scaffolding techniques used with different expertise levels.

With bachelor students scaffolding was used 45 times during oral presentations by five groups. Fourteen times the result of scaffolding was clearly effective, 5 times it was not effective and required further scaffolding, and on other occasions the result could not be identified. This was expected as some scaffolding techniques serve as illustrating a point by providing examples or explanations and do not require a response (but may contribute to understanding nevertheless). Eight different scaffolding techniques were used, see Table 3.

As can be seen from the frequency of use, facilitators used providing examples (EX) and asking leading questions (QUES) most often. For example (translation from Estonian):

(BA_G4) Facilitator II: Yes, this is self-plagiarism and there are very serious consequences not only to the author, but also the reputation of the institution may be destroyed, so one should be extremely careful. (EX)

\section{(BA_G1) Facilitator I: Will you need a data management plan? (QUES)}

Examples (EX) do not usually require a response from the learners, so it is difficult to evaluate the effectiveness of that scaffolding technique but asking a leading question (QUES) usually proved to be effective (6 times out of 10).

With the MA group scaffolding was used 92 times during the presentations by five groups, 22 times the result of scaffolding was effective, 12 times it was not effective and on other occasions it cannot be identified. Also, 8 different scaffolding techniques were used, see Table 3.

Again, facilitators used providing examples (EX) and asking leading questions (QUES) most often. Asking a leading question proved to be the most effective technique, still provided 
a positive response only once in three times, examples were even less effective $-15 \%$ of the time. Pumping was needed more with 2 groups (e.g. Do you have any other topics to discuss?). Highlighting a critical issue (HIGH) was mostly effective (but not used very often), as was maintaining the goal (GOAL). For example (translation from Estonian):

(MA_G4) Facilitator 1: I'd like to draw your attention to something you have not mentioned - it is not particularly ethical to send the manuscript to several journals in order to see if you can get published. (GOAL)

Student 1: We forgot to add that it is probably not ethical to send the manuscript into two journals at the same time...

Facilitator I: What is this connected with? (QUES) Think of question number two - Is reviewing articles time consuming and lots of work - if two reviewers have to do the reviewing then this is their time and work. (HIGH).

There were $2 \mathrm{PhD}$ level groups, facilitators used scaffolding 17 times, which was mostly effective in helping students move forward (continue their discussion on the given topic), but not really increasing their understanding. Five different scaffolding techniques were used, see Table 3.

Highlighting critical features (HIGH) proved to be most effective, often combined with asking a leading question (QUES) or providing an example (EX):

(PhD_G1) Facilitator 1: You are planning this research (HIGH) - what do you need to do? (QUES)

Student I: OK then the problem is that we have to ask permission of the girls and of the parents of the girls.

Still, the technique increasing understanding for these groups was pumping (PUMP):

(PhD_G2) Facilitator 1: any other questions you would like to comment on? (PUMP)

Student I: Yes [short pause] - 'who are the authors of the publication' - we wrote that the authors of the publication are - because it said 'you and your team' we said 'me and my team'.

Pumping (PUMP) proved to be effective every time, as were filling-in-the-blank requests (FILL) and comparing a current problem to a previous on (PREV), but the latter two were only used once.

Often, scaffolding techniques were used in combinations, for example providing an example (EX) and asking a leading question (QUES), extending the case (EXTEN) and describing the problem to direct focus (DIRF), or extending the case (EXTEN) and asking a leading question (QUES), these combinations usually proved to be mostly effective:

(PhD_G1)

Facilitator II: you have been changing the narrative, you had blood samples at first, but not later. Collecting blood samples has a great influence on your data collection and storage. $(E X)$.

Student I - because in the beginning we thought it was given to us, but then we realised we have to invent the context for it, so ...

Prompter II - but you invented the context of blood samples, how does that influence your [research]? (QUES).

Student I - slightly, it will influence it slightly, cause ... and we also realised ...

Prompter II - what do you mean by 'slightly'? What is the main difference? (QUES/HIGH).

Student I - ethics and permission and ... all sorts of rules we have to follow...

Prompter II - [continues the list] ... how do you store it afterwards? The samples. (QUES/HIGH).

Student I - disposal of samples [agreeing murmur by the group]. 
Overall, $\mathrm{PhD}$ groups were very different - while one group received a lot of scaffolding (15 times), the other group only received pumping (twice), which seemed to be enough for them. It can be said that groups can be very different and averages are difficult to bring out based on just two $\mathrm{PhD}$ level groups.

\section{Advanced Level Scaffolding}

The analysis of structural scaffolding (based on the ECAG, Tammeleht et al. 2019) revealed that decomposing the task was effective for all Advanced level groups. As the Advanced level workshop design was different from the Foundation level, the groups did not write the report paper and used only collaborative discussion, the structural and oral scaffolding is analysed simultaneously in the section below,

In the scaffolded supervisor group scaffolding was used 27 times, 6 different techniques were used, out of which $39 \%$ of the time it was maintaining goal orientation (GOAL). $22 \%$ of the time it was making fill-in-the-blank questions (FILL) and others were used less. Peer scaffolding was used twice. Scaffolding was effective $56 \%$ of the time, it was not effective $22 \%$ of the time, for other times it could not be identified. This was expected as some scaffolding techniques serve as illustrating a point by providing examples or explanations and do not require a response (but may contribute to understanding nevertheless). Six different scaffolding techniques were used, see Table 3.

For supervisors it seemed especially important to remind them of certain aspects of the task - they have lots of experience and like sharing it, they tend to bring in their personal stories and the connection between the case and their own story might not always be clear. Still, the group did not ask for clarification even if such an intervention happened. For example:

(S_Ad_G1) Facilitator: OK, can we move on to the second question that [was] opened who are the stakeholders in this case? (GOAL - scaffolding was used to finish the discussion on the previous topic, the discussion did not show indications of ending)

In the un-scaffolded supervisor group scaffolding was used 7 times, out of which 4 times it was peer scaffolding, scaffolding was effective every time. Again, the most used technique was maintaining goal orientation. Four different scaffolding techniques were used, see Table 3.

Scaffolding was used less for this group as the prompter kept a distance and only provided help in case asked or it could be seen that the discussion was disrupted. For example:

(S_Ad_G2) Person 1 - I know that some people in our university believe that you should put the name of your supervisor at all your presentations as a co-author, even if the supervisor didn't really co-author the presentation, cause he is your supervisor. So, that kind of thinking exists as well.

Person 3 - mmm, in our institution .. anyway, let's move on. [feel a bit lost].

Facilitator - next one is stakeholders - who are the ones who are somehow affected by that situation. (GOAL).

Analysis of the discussion showed that scaffolding would have helped to keep the discussion within a given frame - both by time and topic/scope. Supervisors are able to rephrase the idea in several ways and thus keep on talking about the same aspect without really adding anything new - they could have used scaffolding to stop the discussion when nothing new was added. Another place the supervisors could have used scaffolding was to stop speculations - in this case the speculations took them quite far from the original case and this started to influence their final outcome (providing possible courses of action) as they were influenced by the 
speculations they had brought into the discussion. Maintaining goal orientation technique would have worked in those cases as well.

In the $\mathrm{PhD}$ student group, who dealt with an advanced level case, scaffolding was used 44 times, 10 different techniques were used, peer scaffolding 4 times. $71 \%$ of the time scaffolding was effective, in $11 \%$ of the time it was not effective and for other times it could not be identified. See Table 3 for the techniques used.

There was no one more dominant technique for the $\mathrm{PhD}$ student group, techniques GOAL, QUES, PUMP, RDIR and EXE were used more. For example:

(PhD_Ad) Facilitator: but you can't study something like that if you tell them that I'm going to see if there's discriminatory ... (GOAL)

Person 1: yeah-yeah, I think they don't know anything, because otherwise you can't...

Facilitator: does that mean they don't have any rights? (QUES).

Person 1: they still have rights, but .. like if... like if someone, like, wants to steal from my home, I don't know their plan, I still have rights, but I will apply them later.

Facilitator: but do you see that we also have a .. another principle here - that they don't know... (GOAL).

Person 1: that they are gonna be researched like that.

Facilitator: and then maybe harms their ...reputation ... (EX).

Person 1: definitely [group talking at the same time].

Person 3: but they should know it, but sometimes it's done a little bit later, because if you do it at the beginning, it could influence the result of the research. [group agrees, speak at the same time].

Table 5 Scaffolding pattern for bachelor group 3 (Foundation level). Grey cells signify effective scaffolding, white - no evidence of effectiveness

\begin{tabular}{|c|c|c|c|c|c|c|c|c|}
\hline & \multicolumn{8}{|c|}{ Sequence of scaffolding intervention } \\
\hline Process & 1 & 2 & 3 & 4 & 5 & 6 & 7 & 8 \\
\hline $\begin{array}{l}\text { Sense- } \\
\text { making }\end{array}$ & QUES & & QUES & & & QUES & DIRF & DIRF \\
\hline $\begin{array}{l}\text { Process } \\
\text { management }\end{array}$ & & & & & & & & \\
\hline $\begin{array}{l}\text { Articulation } \\
\text { and } \\
\text { reflection }\end{array}$ & & EXTE & & EXTE & EXTE & & & \\
\hline
\end{tabular}




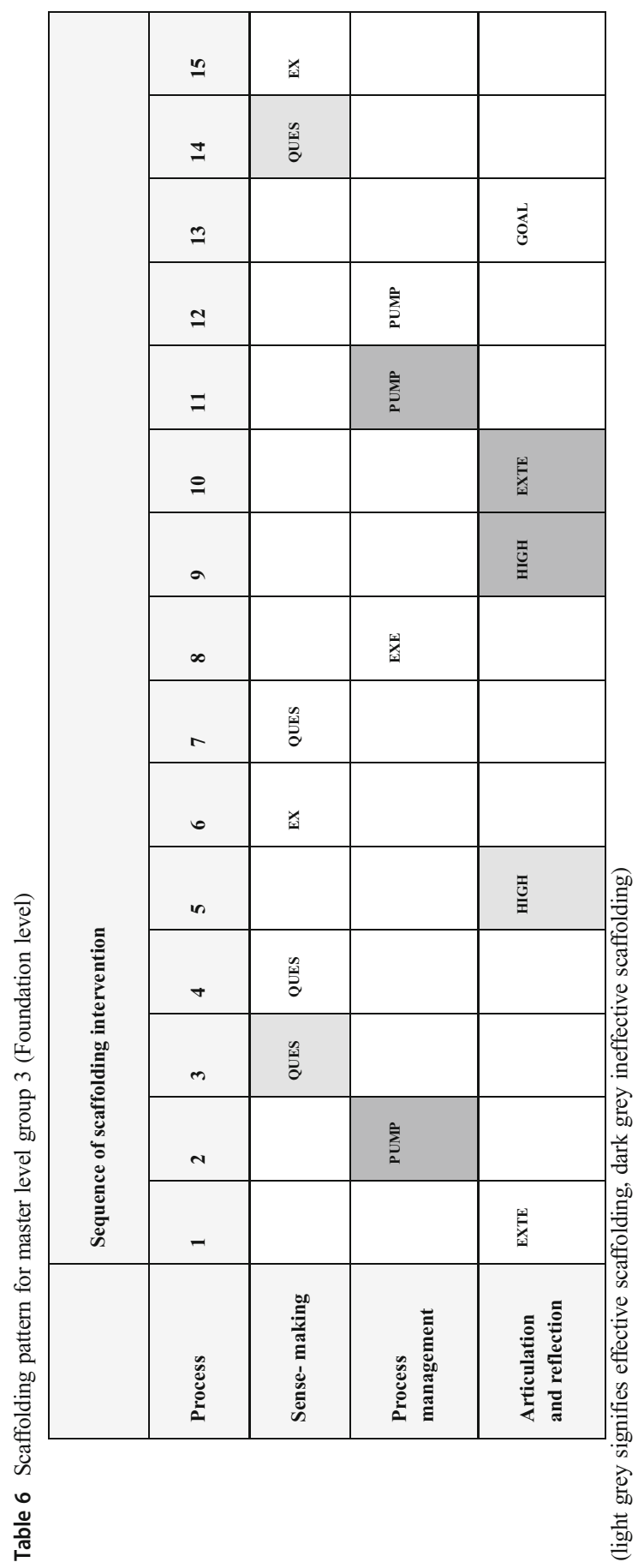




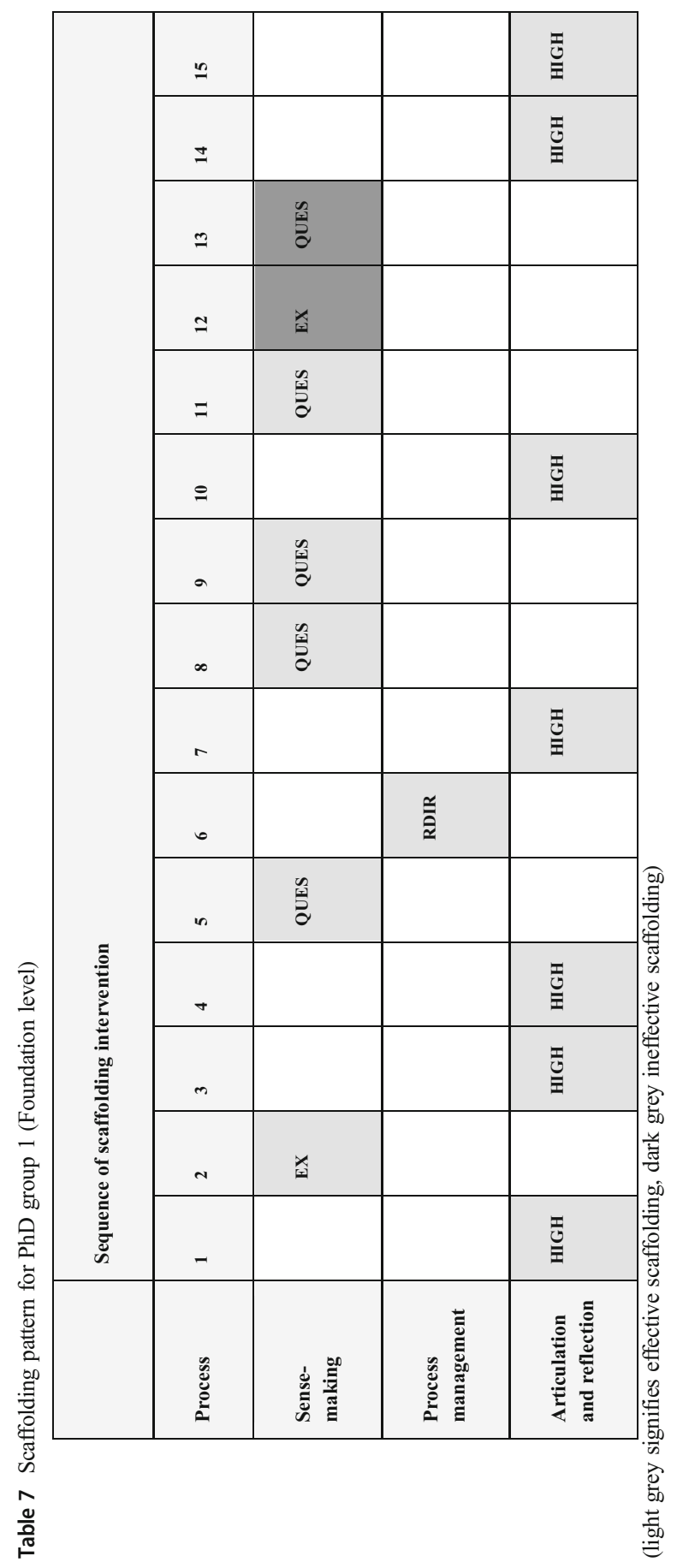


Overall, there could have been less technique EXE (used 6 times during the discussion) as this is basically providing the learners with the answer (to support the flow of the discussion), the participants also said in the feedback round that they would have managed without the answers given during the discussion.

For the last part of the group discussion, the facilitator left the group to allow less scaffolding and the group managed well - they used maintaining goal orientation (GOAL) once (as peer scaffolding). Doing previous tasks had prepared the group for the final discussion and the group exhibited advanced understanding, for example:

(PhD_Ad) Student 2: but then this place - being faithful ummm ... it's ... it should be then later informed that which were the calls that pretended to seek for job and which were not, so the human resources staff would know .. ummm... so they wouldn't start to ... really they wanted to hire ... they got a good worker and then they withdrew, turns out it was a fake. Because that would violate this being faithful (group agrees).

Student 3: it's a good point.

Student 2: so we could try to get informed consent before, by saying within this time-frame and the different people doing and then later we should inform them which were the fake applications ... who were the fake ones for the job (group agrees). Yeah, but I think maybe to have volunteers who really ask for a job that would be beneficial, because then they would get a job.

Student 1: yeah, yeah [general agreement].

Student 2: then it would be useful for the human resources ...

Student 1: and they have to maybe make not false calls, but in the end they.. get the job.

It can be seen from the extract that the learners were thinking about the positive outcomes for everyone, aiming for the greater good. In addition, the group showed advanced understanding as they were referring to previous tasks ('being faithful' - an ethical principle from task 1, considering various stakeholders from task 2, see the Appendix for workshop description), and provided possible courses of action that would be beneficial for everyone. Also, withdrawing the facilitator and scaffolding happened at the right time as the group proceeded without any support.

\section{Scaffolding Patterns}

We then analysed the similarities and differences between various expertise levels.

Bachelor level groups spent about 4-6 min to present their ideas on the case and received scaffolding within that time. On average, each group received oral scaffolding about 7 times per presentation (see Table 5 exemplifying the scaffolding pattern of one bachelor level group). About $30 \%$ of the scaffolding was effective (resulting in an increase of understanding or discussion). Bachelor level groups received scaffolding on 13 different topics, out of which 8 topics were factual in nature and 5 were analytic - scaffolding was more effective for analytic topics as students required help to analyse the context and this was not provided by the task design. Bachelor students showed sensitivity towards ethical issue when provided suitable forms of scaffolding.

Master level groups spent about 9-10 min on their presentations receiving oral scaffolding about 16 times per group (see Table 6 exemplifying the scaffolding pattern of one master level group). About $20 \%$ of the scaffolding was effective (i.e. resulting in increase of understanding). Master level groups received scaffolding on 26 topics - out of which 13 topics were factual and 13 topics were analytic, scaffolding was equally effective for both kinds of topics 
(even though only in few occasions). Master level groups received significantly more scaffolding, still, they made very little progress compared to bachelor level groups.

There were two $\mathrm{PhD}$ level groups (dealing with Foundation level cases) with very different scaffolding they received, which makes comparison difficult. Table 7 visualises the scaffolding pattern for the group that received significantly more oral scaffolding. Still, it can be said that $\mathrm{PhD}$ level groups do not seem to need or benefit from oral scaffolding to a great extent. Their biggest need for scaffolding might be maintaining the goal and not losing the focus of the case. This kind of scaffolding could be included into the design of training materials.

For advanced level groups there seems to be a need for maintaining goal orientation - both supervisors and $\mathrm{PhD}$ students have experience in research and ethical issues connected with it. This can be an advantage and a disadvantage - while experience can help recognise ethical issues more easily, the experience may also start interfering with the case at hand - people start bringing in their own cases (whether they are connected with the present case or not) and speculate on aspects that are actually not connected with the case. This was especially visible with the supervisor groups. This makes scaffolding for goal orientation crucial - it can be in the form of pumping (PUMP), redirecting the learner (RDIR), maintaining goal orientation (GOAL), making a fill-in-the-blank requests (FILL), asking a leading question (QUES) or highlighting a critical feature (HIGH) - all of the above are structural forms of scaffolding and can be written in the task design and training material. The mentioned scaffolding techniques would also help limit time and scope of the discussion.

An interesting difference of peer scaffolding difference appeared between supervisor and $\mathrm{PhD}$ student groups - while $\mathrm{PhD}$ students freely confronted each other offering thus peer scaffolding (e.g. asking for clarification of an idea the other group member had offered, openly disagreeing but also providing reasons for it), supervisors did not do that. When one of the supervisors offered an example or an explanation, others agreed immediately, even though it was not always obvious why this explanation was given or how it was connected with the case. The supervisors may be more oriented to maintaining pleasant relationships rather than challenging each other.

\section{Discussion}

In this article we evaluated the necessity and effectiveness of scaffolding during ethics training in HE context. We focused on 3 research questions: Which scaffolding techniques were used? Were the used scaffolding techniques effective? What were the similarities and differences of scaffolding techniques between various expertise levels? Scaffolding in our study referred to support provided to learners and then reducing it as the competence grew. Even though most scaffolding studies focus on children and cognitive learning, we can claim that scaffolding is also needed in HE context and can be very effective in supporting the acquisition of ethics competencies when utilising an appropriate scaffolding framework.

Scaffolding may come in different forms. We were interested in which scaffolding techniques and mechanisms can be used in ethics training. In our study we focused on structural and oral scaffolding. Structural scaffolding can be written in the task design (instructions for learning), oral scaffolding is provided by a facilitator and is based on the needs of the learner (indicated as 'structural' and 'problematising' in Reiser 2004). When in the past scaffolding was seen as a one-to-one process, then recently scaffolding theories have moved into 
classrooms, and already this poses various challenges. Puntambekar and Hübscher (2005) highlight the challenges of classroom scaffolding where the teacher cannot cater for the needs of all the students and most of it must be included in the task design (but that would not be suitable for everyone).

Our goal was also to evaluate the effectiveness of the used scaffolding. Indeed, our study revealed that structural scaffolding alone is not always effective with students of limited prior knowledge. Especially for bachelor students, oral scaffolding became crucial in order to advance their understanding. This is also supported by Raes et al. (2012) who claim that learners with limited prior knowledge require more oral scaffolding. In addition, as also stated in the prior research (e.g. Raes et al. 2012), more advanced learners can advance their understanding with just structural scaffolding. This was supported by our findings as both master's and doctoral students benefited most from just wording the ethical issue used in task 2 (as a form of structural scaffolding). Students of bachelor level seem to require help dealing with analytic topics, sometimes also with facts pertaining to certain regulations in ethics. Bachelor students need facilitators to provide help as the need becomes apparent, especially to understand concepts. Indeed, our analysis revealed that the most used and also effective scaffolding techniques used with bachelor students were providing examples and asking leading questions, which both support sense-making. Quintana et al. (2004) also highlight in their study that supporting sense-making is the foundation for understanding and has to precede higher levels of understanding and reflection.

The comparison of different expertise levels gave us some valuable insights. While bachelor level students needed help with sense-making, master level students did not benefit from the same scaffolding techniques. For them, wording the ethical issues (task 2 in the workshop) was the most beneficial (structural) scaffold. We also saw that master level students did not benefit greatly from oral scaffolding (even though they received more than twice as much of it than bachelor level students). The reason might be the lowered ethical sensitivity during master studies, highlighted already by previous research (Rissanen \& Löfström 2014; Sparks and Hunt 1998; Niemi 2016).

Doctoral students and also supervisors received scaffolding techniques that supported maintaining goal orientation, highlighting critical features and keeping a focus (e.g. by pumping). For doctoral students also wording the ethical issues and asking a direct question helped advance their understanding. It seems that more advanced level learners require support in process management and articulation and reflection. Raes et al. (2012) also support this outcome and state that more advanced learners can cope well with support included in the task design and are ready to get less scaffolding (so scaffolding fades). For more advanced doctoral students as well as supervisors the main scaffolding need seemed to be maintaining goal orientation and focusing on the case at hand. With additional structural scaffolds in the task design, this can easily be achieved.

The analysis of turns of scaffolding techniques in time revealed that scaffolding is not linear in scaffolding process (proposed by Quintana et al. 2004). Indeed, scaffolding should first support sense-making as otherwise the learner may not understand more complex problems. Then scaffolding could focus on process management if the need becomes apparent. Nevertheless, if, for example, during the articulation and reflection phase it becomes apparent that the learners had misunderstood a certain aspect of the concept, the scaffolding should return to sense-making techniques to pinpoint discrepancies. Generally, scaffolding fluctuates between different scaffolding processes as the need becomes apparent. In addition, we would suggest that even though we did not have specific scaffolding training for the facilitators, this study will help to develop such training. 


\section{Recommendations}

Based on our study we make recommendations to facilitators of ethics training:

- Scaffolding process: Students with limited prior knowledge require a facilitator to provide scaffolding when the need becomes apparent. The facilitator should be able to diagnose which topics are problematic to learners and evaluate how much scaffolding and when to provide it. Usually, beginners require help with sense-making as this is a prerequisite for analysis and reflection (see the appropriate scaffolding techniques in Table 1). In addition, it can be expected that scaffolding process is not linear and facilitators should use techniques flexibly.

- Scaffolding mechanisms and techniques: all levels of learners benefit from process management and structural scaffolding. When designing learning tasks facilitators should consider which structural scaffolding techniques could be included to help learners manage their learning process - e.g. decomposing the bigger task into smaller steps, handing out tasks one after another, providing guiding questions.

- Ethical sensitivity and previous knowledge: there are various suggestions on how to deal with lowered ethical sensitivity pedagogically, but most of them require a wider training plan than just one workshop. Niemi (2016) suggests raising the students' awareness towards the challenges in ethical conduct by developing a wider training plan which would include students compiling portfolios, essay assignments, learning diaries, observing the researchers at work, personal reflection tasks, multi-sided analysis of cases on a regular basis, and so on. It should also be remembered that codes of conduct and regulations may change and it is advisable to keep an eye on them even if one feels competent in their research field. This may apply to more advanced learners who feel confident about their expertise and may neglect regulations.

Overall, we see that the direct scaffolding framework could also be utilised to support complex problem solving not only in ethics education, but also e.g. supervisory relationships.

\section{Future Studies}

In the current study, the ethics training sessions followed two separate formats which makes their direct comparison challenging. In addition, the interventions were mostly facilitated by two people, even though expert teachers, still resulting in introduced variance due to the facilitator and their teaching style. As the student groups were randomly compiled, student personalities and group dynamics may have also influenced the scaffolding response. As we cannot correct for these factors in the current study, future studies are needed that focus on group dynamics during ethics training. Moreover, scrutinising student group and teacher talking (scaffolding) time ratios may give valuable insights to understanding the student-led learning.

Authors'Contributions AT created the research concept and designed the training and assessment materials for the research purposes, acquired, analysed and interpreted the collected data, wrote and revised the manuscript. MJR-T analysed and interpreted the data, created the aggregated dataset, visualised the research results, substantially revised the manuscript. KK conducted trainings and acquired data, supported research design, drafted and revised the manuscript. EL created the research 
concept and helped design the training materials, interpreted results, substantially revised the manuscript. All authors read and approved the final manuscript.

Funding Information Open access funding provided by University of Helsinki including Helsinki University Central Hospital, Erasmus+ (2017-1-ES01-KA203-038303) Anu Tammeleht, Horizon 2020 (669074) María Jesús Rodríguez-Triana.

\section{Appendix - Description of research ethics workshops}

For the research purpose research ethics workshops were designed that utilised cases, collaboration, and structural and oral scaffolding. There were two different formats of dealing with cases - the first format (Foundation Level) consisted of groups initially dealing with ethics cases independently (receiving only structural scaffolding provided by the design of the tasks), then presenting the results and simultaneously receiving oral scaffolding by facilitators. The other format (Advanced Level) consisted of groups dealing with cases and simultaneously receiving structural and oral scaffolding.

The Foundation level workshop for bachelor, master and beginner doctoral students followed a predefined structure (to provide structural scaffolding) with a prior task, working on the case, presenting it and reflecting on learning:

1 Pre-practice questions were designed to attune the students for the topic and map their initial awareness. This took about $5 \mathrm{~min}$.

2 Task 1 - groups received a case with relatively general and open-ended content. They were asked to come up with an example related to their field (the cases were applicable for different fields) and to define a context to the ethical issues. The first step was to mark on the report sheet (underlying/circling/taking notes) which ethical issues they recognised (both explicit and implicit). The groups had about 10-15 min to do this. The following is an example of a case:

The research institution turns to you to take over a part of a bigger survey (e.g. an Erasmus project). The subjects of your research will be girls in their early teens (as an alternative-you are collecting data from a sensitive sample - rare artefacts/endangered plants), the results will be published in an international journal. You agree and start your planning. Which ethical issues might emerge?

3. Task 2 - the groups were given guiding questions about the case drawing attention to various issues (topics) characteristic of the research phase, i.e. planning, conducting or publishing. The topics students were expected to discuss were based on contents in the ALLEA Code of Conduct for Research Integrity (2017). The groups were prompted to utilise the European and the national codes of conduct. The groups had about 20$30 \mathrm{~min}$ to discuss the questions. For example, for the case above, some of the questions were:

Which codes of conduct do you follow? Are you familiar with them? Where to find them? Are there special requirements and protocols for handling these subjects? Is an ethics review required? What determines this? What is the impact of your research? 
4. Task 3 - the group was given support material - outlining the topics of the case accompanied by comments and references to rules and regulations pertaining to them, the groups elaborated the answers (in a different colour), the groups spent about 15-20 min for this.

5 Task 4 - the groups gave overviews of their cases to other groups (thus covering all the phases of research) - this task was scaffolded by one or two facilitators. All other students were encouraged to join in with questions and comments. Each group got about $15 \mathrm{~min}$ on the overview.

6 All students who participated in the workshop were asked to fill in the feedback form (individually) in order to evaluate the outcome and awareness development of participants.

The Advanced level ethics workshop (designed primarily for the more experienced $\mathrm{PhD}$ students and junior and senior academics) consisted of cases that groups discussed collaboratively following a set of tasks:

An example task:

You have early stage researchers in your team, who work on your project and whom you mentor. They are
responsible for conducting a part of a bigger research on discriminatory practices in workplaces, and you
want to make sure they do it in accordance with the relevant procedures and regulations. Some of the
researchers will act as job seekers of ethnic background. They will call employers and monitor employers'
reactions to the information about their background. The employers will not know their reactions are target of
scientific research. The scientific contribution of the project is that it helps to reveal how discriminatory
practices may emerge and how common they are across job sectors.

Task 1: recognising ethical dilemmas/principles (Kitchener's (1992) principles given to groups).

Identify which ethical issues could emerge in this case.

Identify which ethical principles may be present in this case, justify your answers/give examples:

respect for autonomy

doing no harm (non maleficence)

benefiting others (beneficence)

being just (justice)

being faithful (fidelity)

Task 2: identifying stakeholders (their rights and responsibilities).

Task 3: possible courses of action (and their implications).

The tasks were given to groups one after another after they had finished the previous one. The groups got about 25-30 min on the whole exercise.

Open Access This article is licensed under a Creative Commons Attribution 4.0 International License, which permits use, sharing, adaptation, distribution and reproduction in any medium or format, as long as you give appropriate credit to the original author(s) and the source, provide a link to the Creative Commons licence, and indicate if changes were made. The images or other third party material in this article are included in the article's Creative Commons licence, unless indicated otherwise in a credit line to the material. If material is not included in the article's Creative Commons licence and your intended use is not permitted by statutory regulation or exceeds the permitted use, you will need to obtain permission directly from the copyright holder. To view a copy of this licence, visit http://creativecommons.org/licenses/by/4.0/.

\section{References}

ALLEA. (2017). The European code of conduct for research integrity. Berlin: Retrieved from: www.allea.org. Bertram Gallant, T. (Ed.). (2011). Creating the ethical academy: A systems approach to understanding misconduct and empowering change. New York: Routledge. 
Chi, M. T., Siler, S. A., Jeong, H., Yamauchi, T., \& Hausmann, R. G. (2001). Learning from human tutoring. Cognitive Science, 25(4), 471-533.

Dempsey, M., Halton, C., \& Murphy, M. (2001). Reflective learning in social work education: Scaffolding the process. Social Work Education, 20(6), 631-641 https://doi.org/10.1080/02615470120089825.

Finnish Advisory Board on Research Ethics. (2009). Ethical principles of research in the humanities and social and behavioural sciences and proposals for ethical review National Advisory Board on research ethics. Helsinki Retrieved from: https://www.tenk.fi/sites/tenk.fi/files/ethicalprinciples.pdf.

Jackson, D., Sibson, R., \& Riebe, L. (2014). Undergraduate perceptions of the development of team-working skills. Education and Training, 56(1), 7-20 https://doi.org/10.1108/ET-01-2013-0002.

Kim, M. C., \& Hannafin, M. J. (2011). Scaffolding 6th graders' problem solving in technology-enhanced science classrooms: A qualitative case study. Instructional Science, 39(3), 255-282 https://doi.org/10.1007/s11251010-9127-4.

Löfström, E., Trotman, T., Furnari, M., \& Shephard, K. (2015). Who teaches academic integrity and how do they teach it? Higher Education, 69(3), 435-448.

Niemi, P. (2016). Six challenges for ethical conduct in science. Science and Engineering Ethics, 22(4), 1007$1025 \mathrm{https}: / /$ doi.org/10.1007/s11948-015-9676-7.

Pijanowski, J. (2009). The role of learning theory in building effective college ethics curricula. Journal of College and Character, 10(3).

Puntambekar, S., \& Hübscher, R. (2005). Tools for scaffolding students in a complex learning environment: What have we gained and what have we missed? Educational Psychologist, 40(1), 1-12 Retrieved from: http://hubscher.org/roland/courses/hf765/readings/EP_puntambekar_hubscher_2005.pdf.

Planas, L. G., \& Nelson, L. E. (2008). A systems approach to scaffold communication skills development. American Journal of Pharmaceutical Education, 72(2) Retrieved from: https://www.ajpe. org/doi/pdf/10.5688/aj720235.

Quintana, C., Reiser, B. J., Davis, E. A., Krajcik, J., Fretz, E., Duncan, R. G., Kyza, E., Edelson, D., \& Soloway, E. (2004). Scaffolding design framework for software to support science inquiry. The Journal of the Learning Sciences, 13(3), 337-386 Retrieved from: http://www.compassproject. net/sadhana/Teaching/readings/13808831.pdf.

Raes, A., Schellens, T., De Wever, B., \& Vanderhoven, E. (2012). Scaffolding information problem solving in web-based collaborative inquiry learning. Computers \& Education, 59, 82-94 https://doi.org/10.1016/j. compedu.2011.11.010.

Reiser, B. J. (2004). Scaffolding complex learning: The mechanisms of structuring and problematizing student work. The Journal of the Learning Sciences, 13, 273-304.

Rissanen, M., \& Löfström, E. (2014). Students' research ethics competences and the university as a learning environment. International Journal for Educational Integrity, 10(2), 17-30 Retrieved from: http://www.ojs. unisa.edu.au/journals/index.php/IJEI/.

Shephard, K., Trotman, T., Furnari, M., \& Löfström, E. (2015). Teaching research integrity in higher education: Policy and strategy. Journal of Higher Education Policy and Management, 37(6), 615-632.

Sparks, J. R., \& Hunt, S. D. (1998). Marketing researcher ethical sensitivity: Conceptualization, measurement, and exploratory investigation. Journal of Marketing, 62(2), 92-109.

Stringer, E. T. (1999). Action Research. Thousands oaks: Cal: Sage Publications.

Tambaum, T. (2017). Teenaged internet tutors' use of scaffolding with older learners. Journal of Adult and Continuing Education, 23(1), 97-118 https://doi.org/10.1177/1477971416672808.

Tammeleht, A., Rodríguez-Triana, M. J., Koort, K., \& Löfström, E. (2019). Collaborative case-based learning process in research ethics. International Journal of Educational Integrity, 15(1), 6 https://doi.org/10.1007 /s40979-019-0043-3.

Tartu University Centre for Ethics \& Research Ethics Council. (2017). Estonian Code of Conduct for Research Integrity. Tartu. Retrieved from: https://www.eetika.ee/sites/default/files/www_ut/hea_teadustava_eng_ trukis.pdf

Turner, V. D., \& Berkowitz, M. W. (2005). Scaffolding morality: Positioning a socio-cultural construct. New Ideas in Psychology, 23(3), 174-184.

Vygotsky, L. (1978). Interaction between learning and development. Readings on the Development of Children, 23(2), 34-41.

Van de Pol, J., Volman, M., \& Beishuizen, J. (2010). Scaffolding in teacher-student interaction: A decade of research. Educational Psychology Review, 22, 271-296 https://doi.org/10.1007/s10648-010-9127-6.

Wood, D., Bruner, J. S., \& Ross, G. (1976). The role of tutoring in problem solving. Journal of Child Psychology and Psychiatry, 17(2), 89-100.

Publisher's Note Springer Nature remains neutral with regard to jurisdictional claims in published maps and institutional affiliations. 